\title{
P2P Users: Important dimensions for changing to legal online music stores
}

\author{
Américo Nobre G. F. Amorim, Jairo S. Dornelas \\ Federal University of Pernambuco \\ Administrative Sciences Department, PROPAD, NEPSI Research Group \\ Av, Prof ${ }^{\circ}$ Moraes Rego, 1235, Recife-PE, 50670-901, Brazil \\ home page: http://www.dca.ufpe.br/nepsi \\ americoamorim@gmail.com, jairo@ufpe.br
}

\begin{abstract}
P2P services made music sharing popular. Users got used to get the songs they want for free, and use it freely, without restrictions. With some years of delay, online music retailers started to sell legal digital song files, mainly with DRM protection. Recent studies shows that P2P networks continue to grow, attracting more and more users. In this scenario, this work is dedicated to find out some evidences about what can be done to convince users to migrate from the P2P services to legal online music stores. The main question that rises is: How to convince users to start paying for what they already find for free? The empirical research was conducted in two phases: First, interviews with 7 specialists from the music and internet businesses (recording companies, music sites, legal online music stores) were done. With the identified practices and insights about the problem, it was created an online survey that was answered by a sample of 10.123 Brazilian online music users. Using a factorial analysis, 3 dimensions (website attributes, competitive differentiation and anti-piracy) were identified. Results indicate that in order to convince users of $\mathrm{P} 2 \mathrm{P}$ services for buying music, the music industry must implement several integrated tactics. In general, website attributes and competitive differentiation are perceived as more important than anti-piracy actions. For occasional users, this process seems to be easier, and might be done with less tactics. The more frequent the P2P usage is, weaker the antipiracy dimension was perceived as important. These findings can indicate that different managerial and marketing approaches are needed to address the migration of users for online legal music stores. Reward programs and exclusive contents seem to be good options in this direction. At last, limitations and suggestions for further studies are presented.
\end{abstract}




\section{Introduction}

The commercial use of Internet started in nineties. In the same period, the audio compression format MP3 (MPEG-1 Audio Layer 3) was developed and released. By allowing the compression of sound files in an average of 11:1 with reasonable audio quality, the MP3 allowed users to transfer audio files on the internet.

In the beginning, only a few websites started offering MP3 files for download. The current internet connections (mainly dial-up) were too slow for transferring song files, and that process took a long time. In this early scenario, no importance was given to MP3 by the music industry. But in 1999, the broadband internet connections were spreading, and a young student created a software called Napster [1]. It allowed its users to easily share and search for music files in a Peer-to-Peer network [2].

Napster was a huge success; millions of users from all over the world learned how to share music. MP3 files have no built-in digital rights management (DRM) so that users can burn them to CDs and transfer to portable audio players (ex: iPod). $\mathrm{P} 2 \mathrm{P}$ services became one of the most popular internet services, and several others followed Napster with more advanced technologies such as Kazaa, Gnutella and eMule.

Then, the music industry started to worry about MP3 and file sharing. In 2000, the Recording Industry Association of America (RIAA) started lawsuits against several music sites, including Napster, which went offline in the same year. But other P2P services survived, and users kept sharing their files. Until 2003, users had no other real option to download songs online. Since there was no good digital music store, they had to use P2P software, and they got used.

The first plausible online music store was Apple's iTunes, released in 2003. The site offered tracks for 99 cents and also full albums, and in its first year it sold 70 million tracks. The marketing mix included cross-selling Apple's digital music player iPod, the product got a huge success, and soon it became one of the company's bestselling products. Following iTunes initiative, in 2004, other players joined the online music market: Wal-Mart, MSN Music, Virgin Music, Sony Connect and MyCokeMusic. Napster also came back as a legal service, offering subscription and also per track sales.

Trying to support the online stores, the music industry continued to fight $\mathrm{P} 2 \mathrm{P}$ software. RIAA changed its tactics in 2004, when started to sue individual users [3] and sabotaging P2P by uploading damaged files. Even with the huge increase in the legal music offer, the P2P services continued to grow. The number of $\mathrm{P} 2 \mathrm{P}$ users seems to double every two years [4]. That clearly shows that a lot more has to be done to transfer users from free $\mathrm{P} 2 \mathrm{P}$ to the legal music businesses.

In this scenario, this research work is dedicated to find out some evidences about what can be done to convince users to migrate from the P2P services to online legal music stores. The main question that rises is: How to convince users to start paying for what they already find for free?

The empirical research was conducted in two phases: First, several interviews with key-specialists from the music and internet businesses (recording companies, music sites, legal online music stores) were done. With the identified practices and 
insights about the problem, it was created an online survey that was answered by more than 8.000 music site users.

\section{Literature Review}

There are several studies about online music distribution, from different areas as computer science, marketing, psychology, law and others. Krueger, Swatman and van der Beek [5] identified that the majority of research focuses on the phenomenon of P2P and its impacts to the music industry and ways that the music industry should react to sales declining. Due to space constrains, the main concepts involved in the phenomena and the pertinent literature will be highlighted.

\subsection{Music as a digital good}

Digital products are described as any form of information that has some meaning and does not need a specific physical exchange media to be carried from the producer to the consumer. As such, most intellectual goods can be labeled digital products, such as: music, software, videos, books, maps, news etc. All of these have content that can be digitalized and transmitted over the internet from the developer to the client [6].

Once within the client's possession, the digital products can be used on the same hardware that provided the internet connection or can be transferred to other physical means of support, for example, music can be burned in CDs or uploaded to digital audio players. Regarding to the business models for music as digital products, there are currently two standards [3]:

- Pay-per-download: Users can buy any song they want and transfer them to portable devices or burn CDs. This model is used by iTunes, MSN Music, Wal-Mart and Tesco (UK).

- Subscription services: Allows users to download a certain number of songs for a period of times. In some services like Napster, songs can be transferred to portable devices and are playable within the subscription time.

Digital products have been conceived as having some specific intrinsic characteristics like: indestructibility; which prevents them from suffering common time effects like traditional goods; transmutability is also present, meaning that consumers can make changes on them; and reproducibility, the most important difference, which makes them easy to copy or reproduce, reducing the marginal cost to almost zero.

According to early estimates [7], the main costs of digital retailers are: rights to publishers and recording labels $(60 \%$ to $70 \%)$, financial transaction (10\% to $15 \%)$, marketing ( $5 \%$ to $10 \%)$, staff $(3 \%$ to $5 \%)$ and internet hosting $(2 \%$ to $5 \%$ ). All these numbers can be minimized due to scale gains, but they are useful for comparing digital distribution to the traditional $C D$, the reproduction cost, internet hosting, is the lowest in music as digital product. 


\subsection{Online Music Marketing}

In order to get in touch with their clients, online music retailers use principles of online marketing applied to the music distribution. Some authors advocate that the traditional marketing approach trough the four P's - Product, Price, Place and Promotion is not the best choice for on-line environments and that it should be replaced by the four C's [8-10]. According to this concept, online retailers should focus on:

- Consumer needs and wants: Needs of consumers are in the center of decisions. Companies should provide new products, including digital products that can be delivered instantly.

- Cost to consumer: Costs should be reduced by the use of e-marketing, and pricing issues must be faced by segmented markets.

- Convenience: Use the Internet as a distribution channel for digital products, direct sales and the presence of the infomediary.

- Communication: The customization is maximized; products and services can be offered by online advertising (banners, email marketing, sponsored links).

Applying the 4C's to the online music distribution marketing mix, Krueger, Lu and Swatman [11] compared two online music retailers with Amazon and eBay. Their conclusions indicate that beyond any pricing strategies, the music industry needs to have the ability to sell online music as a core competence. They argue that this can only be done if clients are treated as allies using communication, convenience and customization tactics to attract new users. The cooperation between music companies must be granted, this is important to enable the offer of a great variety of music, fulfilling the user needs.

\subsection{Digital Rights Management}

In order to sell online music, almost all retailers are required by recording companies to use Digital Rights Management (DRM) technologies. The aim of DRM is to control how digitalized content, such as music, is used by the clients [12]. So when a user buys a song that is DRM-protected, depending on the license, he might not be able to copy it to other computer, burn it to a $\mathrm{CD}$ or transfer the song to a mobile audio player.

The main goal of DRM systems is that they give content producers (artists, publishers, labels) the choice to control how their work will be used by users [13]. On the other hand, consumers get restricted access to goods they paid for. This can lead to serious frustrations and marketing problems, including repudiation of use [14]. Some authors also discuss the adoption of different pricing and DRM levels in the context of piracy [15].

There are different DRM software now available [16], iTunes, for example, uses Advanced Audio Coding together with FairPlay DRM. It allows the clients to burn songs up to $7 \mathrm{CDs}$ and copy files to 5 different computers. Microsoft implemented its 
own DRM in the Windows Media Audio (WMA) file format. WMA is used by several digital music retailers and is compatible with thousands of popular mobile audio players.

\section{Research Method}

In trying to answer our research question, How to convince users to start paying for what they already find for free?, we conducted an empirical research in two phases.

Phase 1. In the exploratory phase, we wanted to find out some evidence and insights of which actions might be taken by online music retailers to attract clients from P2P services. The specialists were asked, by email, to tell any tactic or idea (even if not implemented yet) that could help legal music websites to attract P2P users. They were chosen by two main criteria: experience in online music business and accessibility by the researchers. The final sample contained the seven specialists:

- Two main executives of online digital music retailers;

- One internet anti-piracy specialist, member of one recording companies association.

- One music producer;

- Three founders of popular music websites.

Phase 2. Based on results from Phase 1, a checklist of possible tactics was created. To verify the users' perceptions about these insights, an online survey was created. With 13 questions, the survey covered the checklist topics using a 4-point Likert scale anchored by "No Importance" (1) and "Strong Importance" (4). The survey also had two questions about the user experience in buying songs and using P2P services. A pre-test was conducted with five graduate students from management and computer science courses. At this time, minor adjustments were implemented to make the questions easier to be understood by users.

To select the sample of users that would answer the online survey the main criteria used was the interest of the user in online music. This was done to ensure that the sample would reflect accurate, real results from online music users. After that, researchers contacted one of the most popular Brazilian music websites (sombrasil.com). Since 1998, SomBrasil is one of the most respected and visited music sites in Brazil. Today, it has more than one million page views/day.

With the collaboration of the site, researchers invited by email more than 230,000 users that had subscribed to the website mailing list. The email explained the purposes of the research, described the privacy policy that would be adopted for the respondents and asked for the user's participation by clicking on a special link that would take the user to the survey. The link had a unique random-generated ID, so that each user could only answer the survey once.

The survey was available from December $1^{\text {st }}$ to $5^{\text {th }}, 2005$. It was answered by 10.123 users. Incomplete surveys were discarded, resulting in the total of 8626 valid users for the sample. 


\section{Results Analysis and Discussion}

From the interviews with the specialists (phase 1) and the literature review, a list with the tactics that could be used by online music retailers to convince users to pay was compiled. The analysis of the interviews was done with a content analyses approach, grouping similar answers in tree macro-categories.

Attributes of digital music retailer websites. Almost all specialists talked about some specific characteristics for music retailers websites. In their opinion, if the sites meet several criteria, it's easier for them to attract and retain clients.

- Fast downloads. Sites should have fast Internet hosting, so that users can benefit from their broadband Internet connections without having to wait for other users like in P2P services.

- Security assurance. Sites should guarantee that all files have good sound quality, are complete and virus-free.

- Comprehensive music library. Retailers should offer a wide range of artists, styles and songs, including rare and currently unpublished music.

- Easy to use. Sites should be easy to navigate, search and buy. Search mechanism must help users to find what they want with collateral information such as artist background, related songs and other useful and unavailable information in $\mathrm{P} 2 \mathrm{P}$ services.

- Low prices. Users don't want to spend much money on what they can get for free. Low pricing seems to be one pre-requisite.

- Flexible DRM policies. DRM has to be almost transparent to users. P2P users are used to do everything they want with their files. By putting a lot of restrictions, DRM protected files might be rejected. The trade-off is how to assure a reasonable level of protection without creating trouble to the user.

Value added content provided by retailers. Some specialists argued that in order to convince users to migrate from $\mathrm{P} 2 \mathrm{P}$ to legal services, retailers have to "offer more" than P2P.

- Exclusive bonus contents: Retailers could offer contents that users are not used to find in P2P services such as: extra tracks, remixes, photos, music education content such as lyrics with chords for guitar students.

- Rewards: By buying songs, users would earn points that could be changed to bonus, tickets to shows, souvenirs or even the traditional $C D$.

Music Industry anti-piracy actions. Some specialists believe that anti-piracy measures are essentials for getting users out of P2P. These actions can be taken by recording associations with strong media coverage.

- Artists statements against the use of P2P, asking fans to change to legal services;

- Attack P2P networks by placing corrupted song files on P2P servers and other technological measures to make P2P services worse for their users.

- Take legal action against P2P users and release information about it to the press, creating the sense that using $\mathrm{P} 2 \mathrm{P}$ is risky and illegal.

The survey with music users (Phase 2) was done to identify if the tactics pointed by specialists were perceived as important for online music users. The sample 
revealed that the average respondent was 33 years old, $62 \%$ were males and $38 \%$ females. The first question revealed the $\mathrm{P} 2 \mathrm{P}$ usage frequency of the respondents, as shown in Table 1.

Table 3. P2P Usage frequency for the sample.

\begin{tabular}{ccccc}
\hline Daily & $\begin{array}{c}1 \text { to } 3 \text { times per } \\
\text { week }\end{array}$ & $\begin{array}{r}1 \text { to } 3 \text { times per } \\
\text { month }\end{array}$ & Rarely use & Never use \\
\hline $15,2 \%$ & $14,4 \%$ & $13,3 \%$ & $26,2 \%$ & $30,9 \%$ \\
\hline
\end{tabular}

The second question showed that only $9,4 \%$ of the users had already bought digital music files, while $90,6 \%$ said they never bought digital songs. This might be important information for online retailers of how low their market-share is, at least in the Brazil, where this survey took place.

To analyze the results from the questions about the tactics, we conducted an exploratory factor analysis, trying to identify the main dimensions that were represented by the 11 questions about the tactics. The determinant of the correlation matrix found was .017 , greater than the minimum required of .00001 , showing that multicollinearity is not a problem for the collected data. The KMO value obtained was .898 which means a great value and indicates that factor analysis is appropriate for the data (Kaiser, 1974). All variables also had appropriate values for the measures of sampling adequacy (MSA). The Barlett's Test of sphericity was also significant at the .000 level.

The factor extraction method used was the Principal Component Analysis. To determine the number of the factors for extraction we primarily used the scree plot method [18], which indicated 3 factors. The Eigenvalue for the third component was .972 which is very close to the 1.0 recommendation of Kaiser [19] and also higher than the minimum of .7 described by Jolliffe [20]. It was also used the varimax method for factor rotation. The identified factors explained $64.37 \%$ of the total variance. Reliability analysis was done using the Alpha [21]. According to Malhotra [22], values higher than .5 were accepted.

The factor analysis (see table 2) indicated that the 11 variables could be grouped into 3 factors. Their scores were saved for use in further analysis. The variables grouped into Factor 1 indicated that it clearly represents website attributes. Factor 2 was formed with variables that represent competitive differentiation tactics. Antipiracy actions formed the Factor 3.

In order to understand the influence of P2P usage frequency on each factor, a mean analysis was conducted (see Fig. 1), showing that Competitive Differentiation (F2) and Website Attributes (F1) are generally perceived as more important than Anti-Piracy Actions (F3). To find out if there are significant changes within each factor and the P2P usage frequency, it was conducted a Kruskal-Wallis Mean Test because of the non-parametric data. It indicated that the importance of Factor 1 (Website attributes, $\mathrm{H}(4)=20.11, \mathrm{p}<.05$ ) and Factor 3 (Anti-piracy, $\mathrm{H}(4)=109.1$, $p<.05)$ were significantly affected by the P2P usage frequency.

From this, it's possible to say that, for the studied sample, users that access P2P networks tend to give a slight decreasing importance to website attributes. Daily users perceive this dimension as less important than occasional users. The same 
seems to occur with Anti-Piracy actions (F3) but in a higher degree. Daily users of $\mathrm{P} 2 \mathrm{P}$ services give less important to such dimension than non or occasional users of $\mathrm{P} 2 \mathrm{P}$ services.

Table 4. Factor Analysis Outcomes. (Extraction Method: Principal Component Analysis. Rotation Method: Varimax with Kaiser Normalization)

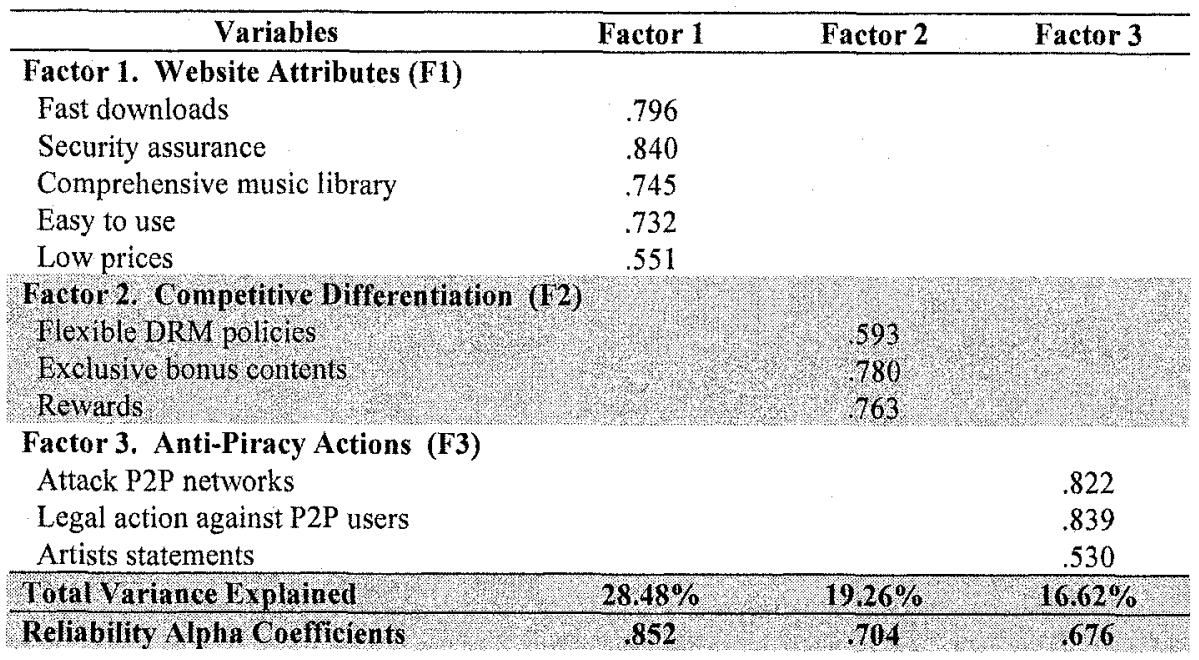




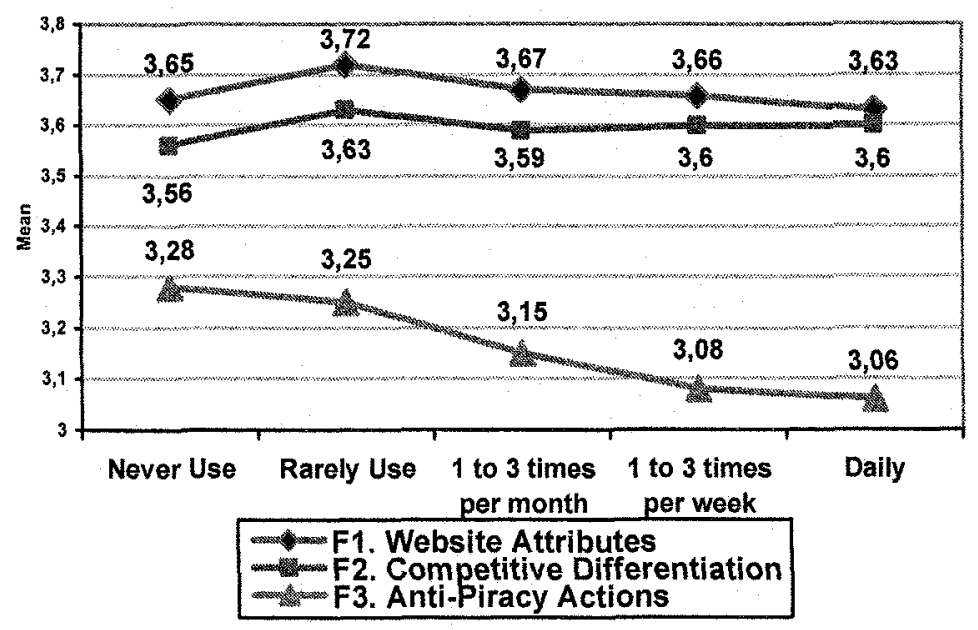

Fig. 4. Factors and the P2P Usage Frequency

\section{Conclusions}

From the research conducted we can conclude that in order to convince users of $\mathrm{P} 2 \mathrm{P}$ services for buying music, retailers and music industry must implement several integrated tactics such as website attributes, competitive differentiation and antipiracy tactics. Website attributes, including usability and pricing issues, has a higher level of perceived importance than anti-piracy measures. That corroborates emarketing literature that defends the business focus on providing the $4 \mathrm{C}$ 's.

The use of isolated anti-piracy actions, which seems to happen in some markets, will not have the desired effect. Anti-Piracy actions seem to be more effective with new clients, which are not frequent P2P users. The significant decrease in the importance of anti-piracy actions for more frequent P2P users seems to indicate that for this group other dimensions are more important.

It's possible to speculate that this behavior shows that frequent users feel much more confident that they will not be affected by anti-piracy actions. That can happen because they believe that their own technology knowledge is sufficient for them to avoid the effects of the various types of attacks against P2P networks (viruses, damaged songs etc). The sense of impunity can also be stronger in frequent P2P users because they might believe that it is difficult to find and prosecute internet crimes, especially for experienced users like themselves.

We can also speculate that anti-piracy actions that are have been implemented, especially legal actions against $\mathrm{P} 2 \mathrm{P}$ users, might have a negative impact, making clients feel as enemies of the music industry. Using Image Theory lens [23], the decision to use illegal songs can be a consequence of the negative image that clients can make about the music companies. This can lead to the emergence of a decision 
pattern where they tend to ignore their normal values and ethics, which usually drive their decisions, and consider the option to pirate as fair in this context. To face this kind of problem, music industry might need to implement what is told on the basic marketing literature: clients must be treated as allies.

At last, it's possible to say that the findings indicate that a deeper marketing approach has to be implemented in order to convince P2P frequent users for buying digital music. Managers might need to focus on offering more benefits for these clients, using joint strategies such as pricing and a better product mix, by adopting some of the competitive differentiation tactics (Flexible DRM policies, Exclusive bonus contents, Rewards etc).

The main limitation of this research is the composition of the sample. Even with a representative amount of users (8626), the results might be slightly different if the survey was ran in other countries, specially in the ones that online retailers are more active and popular. For further studies, we suggest the replication of the e-survey with users from other countries. Another approach would be to trying to identify other variables which would better describe the consumer behavior with digital music. A deeper analysis of the decision process for using illegal files is certainly an important issue, and Image Theory might be one of the plausible approaches for studying this issue.

\section{References}

1. J. Menn, All the Rave: The Rise and Fall of Shawn Fanning's Napster (Crown Business, U.S.A, 2003).

2. Oram, Peer-to-Peer: Harnessing the Power of Disruptive Technologies. (O'Reilly Press, U.S.A, 2001).

3. Digital Music Report, IFPI, 2005, http:/www.ifpi.org/site-content/library/digitalmusic-report-2005.pdf.

4. P2P activity doubles in two years, PC PRO, October 11, 2005, http://www.pcpro.co.uk/news/78525/p2p-activity-doubles-in-two-years.html.

5. C. Krueger, P. M. C. Swatman, K. V. Beek, E-Business Models in the Online Music Sector - A Survey of 10 European Countries, Proceedings of the WEDELMUSIC, 2004 , http://www.cimne.upc.es/simweb/formacion/paperWedel2004.pdf.

6. S. Choi, D. Stahl, A. Whinston, The Economics of Electronic Commerce. (McMillan Technical Publishing, Indianapolis, 1997).

7. Microsoft, again: Apple's old nemesis (CNET, 2003); http://news.com.com/20091027-1009538.html. 
8. R. Lauterborn, New Marketing Litany: 4P's Passe; $C$ words take over (Advertising Age, 1990).

9. P. Kotler, V. Wong, J. Saunders, G. Armstrong, Principles of Marketing, Fourth European Edition (Prentice Hall, 1999).

10. J. Strauss, A. El-Ansary, R. Frost, E-Marketing (Prentice Hall, 2005).

11. C. Krueger, N. Lu, P. M. C. Swatman, Success Factors for Online Music Marketing - eTransformation: From the four P's to the four C's, Proceedings of Collecter, (Latin America, Santiago, Chile, 2003).

12. http://www.cimne.upc.es/simweb/formacion/CollECTeRLatAm2003.pdf.

13. L. S. Sobel, DRM as an Enabler of Business Models: ISPs as Digital Retailers. Berkeley Technology Law Journal (2003);

14. http://www.law.berkeley.edu/journals/btlj/articles/vol18/Sobel.stripped.pdf.

15. W. Rosenblatt, W. Trippe, S. Mooney, Digital Rights Management: Business and Technology (Hungry Minds, Indianapolis, 2001).

16. M. Fetscherin, Consumer acceptance of digital rights management systems. INDICARE Monitor, (v. 2, n. 330 May 2005).

17. http://www.indicare.org/tiki-read_article.php?articleld=105.

18. Sundararajan, Managing Digital Piracy: Pricing and Protection. Information Systems Research. v. 15, i. 3 (2004).

19. M. Peitz, P. Waelbroeck, An Economist's Guide to Digital Music. CESifo Economic Studies. (Munich, 2005); http://www.cesifogroup.de/DocCIDL/econstudies-2-3-05-S359-428.pdf.

20. H. F. Kaiser, An index of factorial simplicity. Psychometrika, v. 39, 1974, pp.31-36.

21. R. B. Cattell, The scree test for the number of factors. Multivariate Behavioral Research, v. 1, 1966, 245-276.

22. H. F. Kaiser, The application of electronic computers to factor analysis. Educational and Psychological Measurement, v. 20, 1960, pp.141-151.

23. T. Jolliffe, Discarding Variables in a Principal Component Analysis. I: Artificial Data. Applied Statistics, v. 21, 1972, pp. 160-173.

24. L. J. Cronbach, Coefficient alpha and the internal structure of tests. Psychometrika, v. 16, 1951, pp.297-334.

25. N. Malhotra, Marketing research: an applied orientation (Prentice-Hall, 1999). 
26. L. R Beach. Image theory: Decision making in personal and organizational context (Chichester, Wiley, 1999). 